of mesmerism are explicable by means of the monotony and consequent exhaustive agency of "the passes." This is a very important point, as it removes all mystery from the subject, and brings it within the sphere of our ordinary and every-day experience.

As regards the so-called higher phenomena of mesmerism-lucidity, phreno-mesmerism, \&c.-I can scarcely imagine any kind or degree of human testimony sufficient for their establishment as facts. And certainly all the evidence heretofore adduced has not been sufficient to remove one particle of that profound improbability which overlies the subject. Every professing clairvoyant who has been subjected to close scrutiny, has entirely failed in his attempt, and has proved nothing except that he is himself an impostor. This holds of every case tested by the committee of the French Academy, to whom science owes much for the care with which they investigated the matter. It holds likewise in the case of Alexis tested by Dr. Forbes; also of one which was exhibited in this city, and was exposed by Dr. Fergusson and others; also of a case tested at Manchester in 1844. The result of all the cases here mentioned has been published, and is well known, so that clairvoyance stands in the predicament of being inherently absurd, opposed to the fundamental principles of human belief, and at the same time utterly unsupported by any evidence. As regards phrenomesmerism, it is enough to say that it presents an example of an ingenious but very unphilosophical mode of reasoning, namely, supporting one very improbable hypothesis by the aid of another almost equally so.

In these-the flourishing days of empiricism in every form, I conceive it to be no less the duty than the interest of the legitimist in medicine, to make himself acquainted with the doctrines of the leading quackeries afloat, so as to enable him to give a reason for their rejection to those who inquire of him concerning them. It is neither wise nor in good taste to be always thrusting our denunciations of this or that empirical system into the teeth of those who believe in them; by so doing we add strength to the delusion. Unless we are appealed to for an opinion, all that is demanded of us is a calm indifference; and if our opinion is asked, as so frequently happens, I believe we shall best consult the interest of legitimate medicine by admitting frankly whatever of truth the particular system under discussion may appear to us to contain, and by pointing out dispassionately where we consider truth to terminate and fiction to commence. By so doing we shall let it appear that our rejection of the system has not arisen from prejudice, or from a want of attention to its claims, but because it presents along with a less or greater substratum of truth, a huge superstructure of assumption and of falsehood.

\section{CASES OF CRANIOTOMY.}

By J OH N S. BA R T R UM, Esq., F.R.C.S., GORGEOX TO THE EASTEBX DIBPENAAB OP BATH

Read before the Bath and Bristol Branch of the Association, MIarch, 1850.

CASE I.-Some years ago I accompanied Mr. Soden to an Irish woman, about 30 , the mother of several children. She had been on the "tramp," and coming in late at night was taken in labour in the morning early. Her powers, from want of food, with prolonged cxertion, were utterly prostrate; the os uteri was not fully open, though dilatable; the uterine pains had wholly left her, and the head had just entered the pelvis, which was well formed. The woman appeared moribund, and it was necessary to act as vigorously as possible. Ergbt, stimulants, and pressure on the uterus, induced no uterine contraction. The head was perforated, and brought down by the craniotomy forceps. The uterus then slowly contracted under firm pressure and the free use of stimulants. There was little or no hæmorrhage, which in her depressed state would probably have been fatal. The woman in the course of some days rallied so much, as within ten days after her labour to be able to walk further on her travels.

The outline of the above case is, I believe, correctly given, it having been firmly impressed on my memory. On a review of it the question arises-Was the practice adopted the correct one? The only other course of proceeding would have been, to the best of my judgment, the passing of the galvanic current through the womb, to excite it to action, as I feel persuaded the turning the child would have endangered the mother's life to an unjustifiable degree in her utterly prostrate state. I do not remember if the head had sufficiently descended to permit the application of the long forceps, but my impression is, that it had not, besides which, the os uteri not being fully dilated, would have precluded their use.

CASE JI.-C. M., about 35 years of age, and three feet three inches high, applied to Mr. Stockwell to attend her in her first labour, she being then in her seventh month. She being so obviously deformed, he most properly determined to induce premature labour not later than the middle of the eighth month, when, if the infant could pass, it might have a chance of living. On examination, we found the pelvis to measure not more than two and a quarter inches antero-posterior diameter, the sacrum jutting very forward, and the bones of the pubes approximating, the pelvis being very deep in its vertical measurement.

May 2nd, 1849.-The membranes were pierced by a male catheter and stilette.

4th.-There were some slight pains, accompanied by discharge of Liquor Amnii.

5th.-Pains much increased; os uteri dilated enough to admit two fingers; the head was felt to present, but 
too high up to ascertain the presentation. At noon the pains were frequent, but the head had not made the least progress.

3 P.M.- The pains have been violent, without any result, and she is becoming very anxious; no further progress being possible, the head was then, with much difficulty, perforated, it being quite above the brim of the pelvis, and only to be reached with the most careful and patient manipulation.

$11 \frac{1}{2}$ P.M. - The head descended a little way; the pains are frequent; pulse rapid; countenance anxious. A full opiate given.

6th, 10 A.M.-Has had a good night; this morning the pains have come on again with vigour, but without forcing the child further into the pelvis.

By the uterine action the position of the fotal head had been altered, and the hole of perforation turned toward one of the pelvic walls, preventing the free evacuation of the contents of the cranium, which consequently could not diminish as it otherwise would have done, therefore at 3 P.M. the head, which was now more within reach, was perforated in a new place and emptied; after this labour was completed in a very short time by the use of the crotchet. The uterus contracted immediately, and threw off the placenta. There was no hæmorrhage. She recovered quickly without a bad symptom.

Should a case of this kind again come under my observation, it would be quite advisable to induce premature labour not later than the end of the sixth or beginning of the seventh month, otherwise the life of the mother would be exposed to the risk of the abdominal section; indeed, if this woman had delayed applying till near her period, no other course would have been open, as it was only with great care and attention that the uterus could be reached to perforate the membranes, and to perforate the head was nearly as difficult.

Case III.-I was sent for on Saturday evening, December, 1849, to a young woman in labour with her first child. She complained most grievously of the premonitory uterine pains, which she stated had kept her awake the two previous nights. On examination I found that the os uteri was scarcely patulous, the vagina lubricated, and the pelvis well formed. Whether the promontory of the sacrum projected I did not note. I gave her twenty minims of the tincture of opium, with directions to repeat the dose in four hours if she got no respite from pain. The two doses produced but little tranquillising effect. In about twelve hours $I$ again saw her, and found the os uteri dilated to the size of a crown piece, thin and rigid, the head high up, and presenting naturally, she having had no sleep, and complaining excessively of pain in the sacrum; she had passed water freely. Matters continued in much the same state for the next twelve hours, the os uteri becoming more patulous, but still thin and rigid, the head not having at all descended into the pelvis. The next night passed without more than snatches of sleep, notwithstanding the most perfect :tranquillity, and a large opiate. The head had not come down, but the scalp was becoming puffed, the fontanelle being directed to the right sacro iliac symphysis. She still complained of intense pains; and there were few or but irregular uterine contractions, producing but little effect on the child, which was felt to be quite lively. The catheter was passed, and about a pint of urine drawn off, without accelerating matters. The Liquor Amnii had drained off, but when I did not discover. There was no thirst; pulse usually quiet, but she constantly implored the use of instruments, of which she seemed to have heard much ; the vagina not heated.

About 3 P.M. of Tuesday, I left her in Mr. Mason's charge, (whose case she was,) fully expecting that some few hours would end the matter, she being quite tranquil in her mind, her pulse having subsided, and having much more confidence in her own powers, though still longing for instruments. The os uteri not yet fully dilated, and thin-edged. There were no uterine pains, and the head had scarcely advanced.

Early in the morning of Wednesday, (the end of the fifth sleepless day,) I was summoned by Mr. Mason to her, whom $I$ found in the most excited semi-delirious state; she could by no means be pacified, insisting on the use of instruments. Pulse nearly 130; tongue becoming dry ; the head had not entered the pelvis, the scalp being more puffed; the os uteri had not altered in character; in fact, all that had been wanted for the past two days was uterine action, which Mr. Mason had tried since I left her to induce by infusion of ergot, without permanent effect.

On the best consideration I thought craniotomy was the only course to pursue, (the state of the os uteri forbade the long forceps, and turning was wholly out of the question,) her state not admitting delay, and delay she would not listen to. Mr. Mason had passed the catheter recently. Without any difficulty the head was perforated, and never have I seen so marked a difference in any patient within some few minutes. The moment the head was but slightly lessened, the system became tranquillised, uterine expulsive pains came on, and within an hour a fine large child was born, the placenta following in an hour without any interference. She then slept placidly, and after some days recovered well, her pulse keeping up to $\mathbf{1 2 0}$ for at least the two subsequent days.

On a calm review of this case $I$ do not think that I could have done otherwise. In the earlier part the exhibition of chloroform might have relieved the intensely-felt pains in the sacrum, which from their reaction on her excitable nervous system, appeared to suspend almost wholly uterine action. At the end of the case, when called in by Mr. Mason, I felt assured that no other course would have been justifiable, for the woman was so restless and unmanageable, and her system so excited, that chloroform was not to be thought of, and it was needful to accomplish delivery as speedily as possible, without adding to the danger of the mother. 